\title{
Information technology risk management teaching exercise: integrating online and offline communication techniques
}

Jenny Gibb, Linda Twiname

University of Waikato

\begin{abstract}
We introduce a risk management project teaching case where students work in consulting teams with a mentor from the information technology industry. The case describes in rich detail the issues and challenges confronting Linny, the owner and CEO of ACE

Technologies, a New Zealand-based software-development firm, as she begins to implement an information technology data exchange trading link between a supplier firm in one country and a logistics company and large buyer firm in another country. Linny calls on Jade Consulting (student groups) to identify potential risks in the implementation process. Taking this case design approach introduces students to two levels of project management education. First, we introduce strategies and techniques to develop e-learning and face-to-face communication skills in a team setting. Second, students manage the stages of a "real" industry project with a mentor. Our findings are relevant for management educators and practitioners involved in project management.
\end{abstract}

Key words: project management, e-learning, risk management, mentoring

This article presents an information technology teaching exercise designed to develop student project management skills, in particular risk management and e-learning communication techniques. This case is especially relevant to management educators in strategic management or information systems. In providing an experiential learning opportunity, students are able to develop and practice multicommunication techniques to communicate with each other, their educator and an industry-expert mentor, to gather and collate the data they require in order to complete this project. We draw on the situatedness of a real business problem condensed into case study format, with the support of an industry-expert mentor (Chandrasekharan \& Osbeck 2010). The article starts with a brief review of the literature on project management and learning design, including e-learning. Next, we provide the case study including the design of learning objectives, the tasks required to engage in the case and then the case is outlined. Throughout, students will be provided with rich opportunities to develop e-learning as well as face-to-face communication techniques in managing a project. This is illustrated through an overview of student feedback from our pretests, post-tests and reflective essays, to illustrate the richness of their learning and engagement.

\section{Literature review}

Project management (Lewis 2007) and computer-based simulation exercises (Schumann, Scott \& Anderson 2006) enable students to engage in learning with heightened authenticity. Exposing management students to such exercises enables them to experience a wide variety of often very challenging situations. Using project management exercises provides management educators with an added advantage, where they can readily adapt the parameters of each project to meet the unique learning requirements of the situation as well as a variety of student capabilities (Bartz 2010). However, once these parameters have been decided, each project requires a clearly defined start and end point and the identification of the required resources and scope of the project (Lewis 2007). 
The industry context used in this article is a risk management setting within the software development industry. By selecting the information communication technology (ICT) we are able to provide students with some current e-learning issues that regularly arise with rapidly changing business and technology conditions.

The risks associated with the ICT sector include firm-specific risks, competitive risks, as well as market and general technology risks. Firm-specific risks are determined by endogenous factors including the firm's ability to align its ICT projects portfolio to business strategy and the skill levels of the ICT staff in communicating with each other and with clients (Angelou $\&$ Economides 2007). Such environments require organisational goals, requirements and assumptions to be clearly defined. It is suggested that an analysis of relationships between these issues be conducted, starting with mapping each of the identified risks and their associated variables. Alternative ways to restructure or adjust behaviours to address problems can then be identified (Abdous \& He 2008).

When students work in group settings they get the opportunity to develop collaborative skills in managing each other while working towards a common goal (Toor 2009; Williams Van Rooij 2009). Furthermore, group-based projects enable students to work with tasks that are typically too complex for one person to handle alone, and thus provide learning experiences in group interaction, giving authentic opportunities for students to articulate and defend their ideas (Collis 1998). Students then need to be guided towards analysing the material gathered and developing an output which may be a virtual presentation or written report. Students should be made aware of the time typically required to complete this step as it is often the longest phase of the project. The next step then becomes one of delivering the outcome of the project to the relevant parties involved (Williams Van Rooij 2009).

A variety of e-learning devices can be used to assist learning in this setting. These include personal computers, Skype networks, text messaging and email systems. The electronic learning arena may include synchronous or asynchronous communication, with the choice of multiple senders and receivers (one-to-one, one-to-many and many-to-many) (Angelou \& Economides 2007). Communication via electronic means provides learners with additional benefits such as the opportunity for immediacy and flexibility. Immediacy refers to communication behaviours that reduce the psychological and social distance between students (Kane \& Goldgehn 2011). Various features such as emoticons on Skype can be used to reduce the psychological distance between group members. Flexibility refers to the advantages the environment provides to students to work at hours and locations convenient to them (Marks, Sibley \& Arbaugh 2005). Electronic means can be supplemented with face-toface contact between team members. Although this hybrid communication design has distinct advantages, it is suggested that care be taken to convey clear expectations to students on how to use each medium. Furthermore, it is important that the educator understands the prior experience and confidence levels of students within each group (Kane \& Goldgehn 2011).

We might ask what other techniques can be used to address some of the challenges involved in teaching project management in a multimedia setting. One such technique is to introduce a hybrid mentoring structure, where an industry-expert mentor works alongside the educator. Industry-expert mentoring relationships have typically been examined in the health and education sectors, particularly for teaching faculty. In such situations employees engage in long term, often self-selected mentor relationships for career building purposes (Brown, Li, Sargent, \& Tasa, 2003). Regardless of whether the mentorees work in industry or are 
management students, the industry-expert mentor will role model appropriate behaviour that integrates his or her knowledge and experience about a particular skill set (Kane \& Goldgehn 2011). This opportunity enables students to observe, actively experiment with and reflect on their performance. Introducing an industry-expert mentor addresses the fact that is not always practical or possible for the educator to be an expert in all areas of learning. However, having an industry-expert mentor does raise a variety of issues for consideration. How should such a person be selected? When should they be involved in the project design? How is the project design going to be monitored and evaluated?

\section{The risk management e-learning teaching project}

The case describes the risk issues and communication challenges confronting Linny, the owner and CEO of ACE Technologies, a New Zealand-based software-development firm, as she starts to implement an information technology data exchange trading link between a supplier firm in New Zealand, and a logistics company and large buyer firm in America. Students are asked to work in consulting teams, where they become Jade Consultants, to assist Linny to identify the potential risks involved in the implementation process and to provide recommendations on how they should be managed. This exercise will provide students with the opportunity to develop and practice their communication skills, in particular their online skills via the use of Skype.

In addition, students have the opportunity to liaise with an expert mentor from the information technology industry, who provides general risk management project experience and guidance. It should be noted that the addition of a mentor is an optional extra. This role could also be taken by the educator. When selecting an expert mentor care should be taken that this person has the willingness, aptitude and time to communicate with and support students as they work through this case.

This case was designed as an information technology teaching exercise to develop project management skills, in particular risk management, e-learning and face-to-face communication within the context of a "real" industry setting. This exercise has been used with year 3 strategic management students completing an undergraduate management degree. It could also be adapted and used in a range of undergraduate or graduate management courses, as an individual or team-based project.

\section{Learning objectives}

In accordance with the general principles of experiential learning (Kolb 1984) and e-learning (Angelou \& Economides 2007), the key learning objectives for the risk management project teaching exercise, include:

- to ensure students can work within a group to plan and communicate the actions needed to complete the required tasks

- to develop skills in how to extract and gather data from a case study exercise

- to develop e-learning and face-to-face skills required to communicate with an industry-expert mentor via a variety of techniques including face-to-face and electronic means, e.g. Skype

- to be able to identify, focus and distil relevant data required in problem solving

- to develop written and oral presentation skills that can be delivered in an online setting to demonstrate mastery of a project management exercise.

In order to achieve these objectives students are required to work through the following three tasks. 


\section{Task 1: Preparation}

Prior to commencing this exercise students are asked to complete an online self-reflection pretest questionnaire to assess their face-to-face and online communication skills, questioning, data gathering, and analysis skills required in project management. Students are asked to complete this same set of items at the end of this exercise, which forms a post-test. It is stressed that we are interested in honest rather than inflated answers; a grade of $1.0 \%$ is given for completing these two tests.

Each student is then required to attend our lecture on risk management, our questioning skills workshop, and to meet the industry-expert mentor. This mentor will begin by providing a face-to-face guest lecture on general project management and risk issues surrounding the development of information technology projects. The mentor will then become available to student teams via Skype.

Students are then asked to self-select into Jade consulting groups where they design a business card and hourly charge-out rate for their services. Students are also asked to prepare an action plan that incorporates e-learning with an online communication plan in order to complete this exercise. Teams are encouraged to make full use of the functionalities available on Skype, including messaging that can be saved, chat and sending documents to each other and the mentor. Their communication plan includes booking two 45-minute Skype meetings with the industry-expert mentor; one in week 1 and the other in week 3 on two prescheduled days. Group members are also asked to identify a key contact person in their group who will be primarily responsible for sending and receiving Skype and email communication with the industry-expert mentor and then to send that person an introductory email.

\section{Task 2: E-Learning and information seeking}

Students are provided with the opportunity to engage in a variety of e-learning modes. They are asked to review the videotaped lectures, online handouts on identifying information technology project risks from the industry-expert mentor and the case study as set out below. The aim is for students to develop an initial understanding of the parameters and likely gaps in the data for the presenting problem(s). For example, the nature of the firms and the employees in each that might contribute to risk situations. Each group then prepares a questionnaire in readiness for their first Skype interview with the industry-expert mentor. This questionnaire is intended to clarify concerns on the material received, and enable students to systematically uncover the presenting risk problems. Students are reminded to concentrate on the processes in order to avoid getting lost in precise information technology jargon or detail. Here the aim is to briefly identify the risks involved at each stage of the implementation process and then to eventually select and concentrate on one particular area of risk, while noting other risk-related areas.

Students groups are aware of the dual role played by the industry-expert mentor. At the first group Skype meeting with the industry-expert mentor, students can indicate if they want to practice with the mentor, before starting their formal interview with that person in their industry-expert role. The industry expert also reserves the right to stop the Skype interview and revert to his or her mentoring role, if it appears the students are becoming confused or are getting off track.

\section{Task 3: Problem solving and presenting a solution}

Students continue to gather and collate data using face-to-face and e-learning techniques as 
they move towards solving the key potential risk problems presented in the case. This process will involve the systematic analysis of all the material gathered from the ongoing interactions with the industry expert and the case study. Student groups can contact the industry expert mentor via short Skype or email communications on a daily basis if desired and will then have one final 45-minute Skype meeting. During these times the industry expert will move to the mentor role when he or she believes student groups need guiding to rethink or reframe their questions or analysis of the situation. The mentor will advise students if the risk situation they are focusing on is too small or insignificant, and also when they have solved the problem. Students are informed at the outset that the industry expert will introduce one piece of information that will be a red herring or falsity. The purpose of the red herring is to simulate a real situation where there may be either some dishonesty or misunderstanding. Several class prompts or hints will be emailed to all groups as a motivating device during the data gathering and analysis stages.

Students are asked to work in their teams to prepare a five-page report that integrates academic and business requirements. This report, which is viewed by the industry-expert mentor will show: (1) the key risk and surrounding risks in the scenario; (2) recommended steps to solve this problem and to mitigate further risks from arising. Students are asked to develop a risk toolkit, for which they will draw on relevant strategic and risk management literature. They are also asked to prepare a 10-minute presentation with accompanying PowerPoint slides to deliver to the class, which is viewed via the Skype video functionality by the industry-expert mentor. Finally, students are required to complete an online post-test questionnaire and to answer one question in their reflective essay, asking for the positive and challenging aspects of this exercise - focusing on the human dimension components of the exercise. (NB: the industry-expert mentor will give an opinion but the educator will provide the final grades).

\section{The case}

Linny arrived at work early on this wintery New Zealand morning. She is about to take an international conference call with the information technology manager at American logistics firm, Grand Falls Lumber. There is a 12-hour time difference between the two countries. As day begins to break, Linny makes some coffee and looks out her window. She can see some ducks waddling through mud as they make their way to the large pond that attracts wildlife behind Linny's office. Linny is reflecting on the great opportunity that lies ahead. Her small information technology company, ACE Technologies Ltd, has just entered into a large ecommerce project with client firm, Juke Timbers Ltd. She is both excited and apprehensive. Linny is very aware that managing data exchange projects, particularly with multiple companies, with some located in other countries never comes without challenges.

Linny had built her electronic data exchange business from a small wife-and-husband business 25 years ago. ACE survived the entry of the internet and electronic commerce, and is now a thriving medium-sized firm in New Zealand terms, with 15 employees. The firm manages a range of national and international data exchange projects between firms, mainly in the fast moving consumer goods and hardware industry sectors. Linny prides herself in her firm's ability to provide a very high standard of electronic data exchange products. She is also aware of her firm's excellent customer relationship record that she has carefully nurtured over time. However, she knows these qualities rest on a fine line that balances managing ongoing customer relationships with potential information technology risks and the delivery of a superior product. 
The project management and e-learning challenge

ACE has just signed a contract to establish an electronic data interchange system between its New Zealand client, supplier firm Juke Timbers, and buyer firm American retail chain Mayhill's. Juke Timbers aims to use Michigan-based logistics company Grand Falls Lumber to deliver its product to Mayhill's. The partnerships will involve extensive use of e-commerce technology for the exchange of transaction data, something Juke Timbers has only limited experience with. Juke Timbers existing system of "faxing" is a far cry from the technology that is required in an e-commerce project. ACE had initially been approached by Juke Timbers Chief Information Officer, Daryl, who had developed a clear plan of what was required with a new electronic data exchange link. However, Daryl has since left Juke Timbers in rather an abrupt manner. Linny is aware that, without Daryl's knowledge at Juke Timbers, she must now consider more carefully how she should begin to manage the project. There are a number of potential risks associated with its implementation.

\section{Current situation}

In preparation for the impending conference call, Linny starts to mull over the steps required to implement the electronic data exchange process. Data tracking will start with Mayhill's, who will send its purchase orders to Juke Timbers. Pick-up orders will then be sent from Juke Timbers to logistics firm, Grand Falls Lumber, for the timber product to be picked, packed and delivered. Juke Timbers will aim to ensure it has sufficient product stored at Grand Falls for this process. At least two hours prior to delivery, an Advanced Shipping Notice (ASN) is needed at the receiving store of Mayhill's. Each pallet of timber product is required to have a Serial Shipping Container Code Label (SSCC) with a scanning code for identification purposes. While the responsibility to get these documents correctly formatted and delivered lies with Grand Falls, Linny is aware that she needs to ascertain how capable the firm is at carrying out such tasks.

After going through the steps required in the data exchange process between Juke Timbers, Grand Falls and Mayhill's, Linny turns to examine the current technological and human expertise she believes each firm in the network has. This is important information that Linny wants to share with Jade Consulting (i.e. student groups), who will assist ACE to identify the risks involved in managing the project.

\section{Mayhills}

Mayhill's is a large hardware retailer in the United States that has 290 retail outlets. The firm has contracted Juke Timbers to supply a range of moulded timber products. Linny understands that Mayhill's first order is due to Juke Timbers at the end of August, which is just two months away. By that time, ACE needs to ensure that an information technology system has been installed and is functioning to connect these key players. The system needs to be able to accurately receive purchase orders, translate them into pick-up orders to enable Grand Falls to deliver the products to the appropriate Mayhill stores.

Mayhill's currently uses a large-scale electronic data interchange (EDI) system with ecommerce communication called AS2 for its orders. It has a sophisticated system that other systems in an electronic data exchange network must fit around. The purchase orders will flow from Mayhill's AS2 system via ACE's ACE-1 EDI system, to Juke Timbers via its TimberSmart system. This is called a valued-added network. The purchase orders will then be filtered by the TimberSmart system operated by Jessica Webber, Juke Timber's US-based account manager. Jessica will then send these as pick-up orders to Grand Falls. Grand Falls must then process each order and arrange shipping, ensuring that the ASN is sent in the right 
time frame and the SSCC label on each pallet is correctly formatted. Grand Falls must also notify Juke Timbers of each shipment in order to enable them to maintain appropriate inventory levels at Grand Falls.

With the assistance of Jade Consulting, ACE is required to create a series of electronic links between Mayhill's, Juke Timbers and Grand Falls' systems. In order to make these links, ACE will need to adjust Juke Timber's and Grand Falls' electronic systems. Changes do not need to be made to Mayhill's EDI system. The respective systems and their links must work perfectly, as Mayhill's regularly issue fines of $\$ 1000$ if an ASN is not delivered two hours prior to delivery of product at their stores and a $\$ 100$ fine if the SSCC label is incorrectly formatted. Juke Timbers would be required to pay any fines.

\section{Juke Timbers Ltd}

This New Zealand firm manufactures a wide range of wood products, specialising in timber mouldings and joinery products. Juke Timbers has 25 employees. Until being approached by Mayhill's it had a number of small national and international customers. With the addition of Mayhill's, as a major customer, the firm is now reviewing its overall operations. ACE has been contracted to extend Juke Timbers current data exchange system, TimberSmart, and also to create the necessary links with the other firms. These changes will enable Jessica Webber, Juke Timber's US-based account manager, to process the purchase orders received from Mayhill's and to send them on to Grand Falls.

ACE will need to extend the functionality of the TimberSmart system and then build an EDI link between Mayhill's and Juke Timbers so that orders can be received via Mayhill's AS2 system. Since Mayhill's is going to be Juke Timbers largest client, Linny understands how important it is that she gets their data exchange process running smoothly. As a part of this, Jessica's responsibility load must be investigated to ascertain whether a safeguard is needed. Linny is aware that in the past Jessica has been rather erratic in her follow-up on projects, which she believes could potentially jeopardise the success of this project. In addition, there does not appear to be any backup person to perform Jessica's tasks when she is absent from work.

\section{Grand Falls}

Grand Falls is an average-sized hardware logistics firm operating in the State of Michigan. After speaking to Jolene Marsh, Grand Falls' yards supervisor, Linny is aware that most of their administration is paper-based, including the documentation with truckdrivers. Linny also ascertained that Grand Falls' computer system is an S2K 1.02 which, she believes, needs a major upgrade to the 3.92 version. In addition to the substantial cost of such an upgrade, it is estimated that the process will take at least two months, followed by an additional one- to two-month implementation period.

At this stage, Linny is unable to ascertain how motivated the management at Grand Falls is to implement an upgrade. She is also questioning to what extent the information technology personnel at Grand Falls have been briefed on the implications of exchanging data with Mayhill's. If Grand Falls chooses not to go ahead with an upgrade, it is still possible for ACE to create an electronic link between their existing system and the other firms; however, the speed of data exchange will be slower.

Strategically managing risk

Conducting business between offices in different countries inevitably presents numerous 
potential communication challenges. After pondering on the reality of the situation, Linny decided that the current opportunity is certainly a great and one ACE could not afford to falter on at any point. She is aware that the value of any electronic data exchange system depends on sound electronic connections being established through robust project management. In order to achieve this, Linny is aware that skilled and reliable staff is required at each step of the process.

Linny decided to call on Jade Consulting (our students) to assist her to identify the potential risks and to develop her electronic communication techniques to facilitate the implementation of this information technology project. She explained to Jade they had a three-week time frame to identify all potential risk situations and to advise on how the implementation process should be managed. Students are asked to follow through the steps involved in completing the three tasks above. We provide in summary format a guide of the key risk indicators (see Appendix 1), a description of that risk, and the priority that risk should be given in the management of the implementation process. We suggest this table be used as a reference for the educator and mentor.

\section{Student feedback}

Next, we provide an overview of student feedback from our pretests, post-tests, and reflective essay assessment requirements. This illustrates the richness of student learning and engagement.

Students indicated, in their pretests that at the beginning of this exercise they experienced a mixed range of emotional states. The pretest questionnaire indicated the predominant presenting emotions were nervousness or tension (75\%) and excitement (20\%). One student reported heightened anxiety levels: "it was a totally new experience for me, I was scared ... having contact with people who are doing business at such a high level ... working with an industry-expert mentor with a real world business problem". Another student reported uncertainty: "I felt so uncomfortable and unsure at the beginning". This student then shared her group's coping strategy: "We found the topic complex at first ... we decided to play to our strengths which was on the technical ... rather than the business side. While other students said they felt very excited with the exercise. One student said: "this is as close as you can actually get ... to actually working with people in business as a professional consultant without actually doing it for real".

The post-test questionnaire indicated the predominant emotional state as alert at this initial point of problem solving. Students reported they found it important to be very organised for their first Skype interview with the expert mentor (approximately 70\%). One student reported: "if you did not prepare enough, you would feel confused ... the key is to be prepared". Another student reported: "We found a lot of questions had to be specific to get an appropriate answer, but if we asked good questions we usually got a more succinct answer".

Student reflective essays can be summed up with one student's comment: "a very positive, realistic, real world experience ... now I feel I can deliver professionally" with the encouragement and support of the industry-expert mentor and educator. Interestingly, by this point, students found that the exercise had enabled them to increase their cognitive, affective and professional skills, as well as to have a closer understanding of the integration between them. Students indicated that the exercise had improved their analytical and problem-solving skills (approximately 95\%). One student reported: "I felt that I learned how to be more efficient, more analytical through having to interpret information and to read between the 
lines ... when dealing with [the industry expert] we got pieces of information, instead of the whole part ... I felt this taught us to be more analytical".

Prompt questions, such as the following, could enhance student reflection as they prepare to write their reflective essays. These questions are based upon our previously stated student learning objectives, and are intended to galvanise student learning:

- How did you work within your group to plan and communicate the actions needed to complete the required tasks?

- What skills did you develop to extract and gather data from a case study exercise?

- What e-learning skills did you develop to communicate with an industry-expert mentor?

- How did you identify, focus upon and distil relevant data required in your problem solving?

- Did you develop written and oral presentation skills? What were they? Please explain how they helped you to demonstrate mastery of the project management exercise?

\section{Instructor feedback}

Next, we identify the lessons we have learned from our risk management project teaching case. First, we have found that the educator and industry-expert mentor are important due to the close and trusting working relationships they create as they direct the general flow of the exercise. To facilitate that relationship, and to keep students on target, we recommend the educator respond daily to students' online questions, particularly during the initial problemsolving stage. Second, some students lost motivation as they worked through the complexities of the project. Consequently, we recommend the educator post weekly problem-solving hints online. We have found this assists us to maintain student motivation. Third, when working through complex scenarios, such as that described here, there is a risk that students will become confused. To maximise student learning experiences, we have learned that we need to keep the problem scenario very clear and succinct and not too complex. We now omit some of the real-world complexity. Fourth, we have found that some students underestimate the time pressures of this exercise, coupled with their general end-of-semester workloads. To maximise our students learning opportunities, we now initiate this exercise at the beginning of the semester. Thus we provide our students with sufficient time to complete the project.

\section{Conclusion}

We have designed and developed an information technology teaching exercise aimed to develop student project management skills, especially their risk management and e-learning communication techniques. This case has drawn on relevant theory in project management and e-learning as well as case material drawn from a real situation confronting an information technology firm. A team approach enables students to gain additional face-to-face and online collaborative skills. Furthermore, we introduced an industry-expert mentor to provide students with the opportunity to practice their e-learning skills, particularly on Skype in a "real" setting.

\section{References}

Abdous, M., \& He, W. 2008. Streamlining the online course development process by using pm tools, The Quarterly Review of Distance Education vol. 9, no. 2, 181-188.

Angelou, G.N., \& Economides, A.A. 2007, E-Learning Investment Risk Management, Information Resources Management Journal, vol. 20, no. 4. 80-104.

Bartz, J. 2010, The learner's place in e-learning project management, Journal of Distance Education, vol. 24, no. 1, 43-54.

Brown, T.C., Li, S.X., Sargent, L.D. \& Tasa, K. 2003, What went wrong at university hospital? An exercise assessing training effectiveness, Journal of Management Education, vol. 27, no. 4. 485-494. 
Chandrasekharan, S. \& Osbeck, L. 2010, Rethinking situatedness: environment structure in the time of the common code, Theory \& Psychology, vol. 20, no. 2, 171-207.

Collis, B. 1998, WWW-based environments for collaborative group work, Education and Information Technologies, vol. 3, 231-245.

Kane, K.R. \& Goldgehn, L.A. 2011, Beyond "the total organization": a graduate-level simulation, Journal of Management Education, vol. 35, no. 4, 344-389.

Kolb, D.A. 1984, Experiential learning: experience as the source of learning and development, Prentice Hall, Englewood Cliffs, NJ.

Lewis, J.P. 2007, Fundamentals of project management ( $3^{\text {rd }}$ ed.), AMACOM, New York.

Li D. \& Shearer, .R 2004, Project management for online course development, Distance Learning, vol. 2, no. 4, 19-23.

Marks, R.B., Sibley, S.D. \& Arbaugh, J.B. 2005, A structural equation model of predictors for effective online learning. Journal of Management Education, vol. 29, no. 4. 531-563

Toor, T.P.S. 2009, People management: an imperative to effective project management, Business Strategy Series, vol. 10, no.1, 40-54.

Williams Van Rooij, S. 2009, Scaffolding project-based learning with the project management body of knowledge (PMBOK), Computers and Education, vol. 52, 210-219.

Acknowledgement and disclaimer: We wish to thank the CEO of an anonymous New Zealand software development firm who provided the initial material for this case. Please note that the names of persons and firms used here are not real names. It should also be noted that the material in this case is not proposed as a criticism to any individuals involved but rather the purpose is to demonstrate the issues involved in initiating an information technology project, particularly the online and offline communication skills required.

\section{About the authors:}

Dr Jenny Gibb is a Senior Lecturer in the Department of Strategy and HRM Management, Waikato Management School, University of Waikato, New Zealand. Her research takes a socioeconomic perspective in examining the interrelationships between individual, firm and network performance. She has published on value creation opportunities via the adoption of information technologies, particularly in electronic networks. She also has a strong pedagogical interest where her focus has been on e-learning and information technologies, including working in virtual teams. Her other area of interest focuses on the micro-foundations of competitive advantage. In particular, she is interested in understanding the foundations of firm-level competitive actions. This includes understanding how key decisionmakers within firms set and adjust their goals that shape these actions. It also includes identifying and explaining how the actions taken by individuals and groups at a microlevel relate to the goals and, ultimately, the firm's performance and competitiveness.

Email: jennyg@waikato.ac.nz

Dr Linda Twiname is a Senior Lecturer in the Department of Strategy and HRM, Waikato Management School, the University of Waikato, New Zealand. Her research explores the human dimension of HRM studies, endorsing sustainable management systems that value interpersonal relationships as key contributors to organisational overall success - both social and financial. She has a particular interest in critical examinations of power relationships within societies and within organisations. Her PhD thesis was titled "In search of wellbeing in the workplace: exploring the emancipatory potential of participatory sction research". Her research contributes to the body of knowledge on participatory action research to facilitate organisational change; and the application of Habermas's concepts of the life world, communicative action, the system and instrumental action. She supports critical analysis of organisational practices including: workplace wellbeing, social responsibility, conflict management, work-life balance, EEO, ethical practices, workplace values, and generally how we might become employers of choice. 


\begin{tabular}{|c|c|c|}
\hline $\begin{array}{l}\text { Estimation } \\
\text { of Impact }\end{array}$ & Description & Indicators \\
\hline \multirow[t]{7}{*}{ High } & $\begin{array}{l}\text { The design, implementation } \\
\text { and/or testing of the system may } \\
\text { fail to meet the project's } \\
\text { requirements }\end{array}$ & $\begin{array}{l}\text { Low in-house expertise at Juke Timbers due to the loss of a } \\
\text { key staff member which may mean the hiring of external } \\
\text { expertise order to deliver on Mayhill's requirements. }\end{array}$ \\
\hline & $\begin{array}{l}\text { Juke Timbers' system is unable } \\
\text { to process the orders from } \\
\text { Mayhill's. }\end{array}$ & $\begin{array}{l}\text { No EDI system is currently set up to receive orders from } \\
\text { Mayhill's AS2system, to transmit them to TimberSmart } \\
\text { system. }\end{array}$ \\
\hline & $\begin{array}{l}\text { Grand Falls' system is barely } \\
\text { capable of processing the orders } \\
\text { ACE sends them and cannot } \\
\text { handle the ASN or SSCC } \\
\text { requirements. }\end{array}$ & $\begin{array}{l}\text { Currently, this is the case. Upgrade of the system to meet } \\
\text { requirements will take approximately } 3-5 \text { months } \\
\text { according to Grand Falls' information technology firm. In } \\
\text { fact, they have not yet been briefed on requirements. }\end{array}$ \\
\hline & $\begin{array}{l}\text { The ASN or SSCC are not } \\
\text { processed correctly by Grand } \\
\text { Falls. }\end{array}$ & $\begin{array}{l}\$ 1000 \text { fine if ASN not delivered at least two hours prior to } \\
\text { delivery of product at stores. } \$ 100 \text { fine if SSCC label not } \\
\text { correctly formatted. The potential impact of errors created } \\
\text { by Grand Falls will be paid by Juke Timbers. At present, } \\
\text { Juke Timbers has very little control over key } \\
\text { communication/delivery factors in the US. If many orders } \\
\text { are placed by Mayhill's but not processed in time by Grant } \\
\text { Falls, then Juke Timbers will have to pay the penalties. } \\
\text { This could be very expensive for Juke Timbers. }\end{array}$ \\
\hline & $\begin{array}{l}\text { Lack of skills and experience of } \\
\text { Grand Falls' staff }\end{array}$ & $\begin{array}{l}\text { Grand Falls' staff is used to paper-based systems. Low } \\
\text { expertise in Grand Falls' staff in using electronic systems. }\end{array}$ \\
\hline & $\begin{array}{l}\text { ACE underperforms because of } \\
\text { its lack of knowledge in } \\
\text { implementing systems in the US }\end{array}$ & $\begin{array}{l}\text { Since ACE is located in New Zealand, it may not be able to } \\
\text { deliver a system based in America. }\end{array}$ \\
\hline & Lack of staff at Juke Timbers & $\begin{array}{l}\text { There is currently one staff member, Jessica Webber, who } \\
\text { is responsible for receiving the orders, cleaning them up } \\
\text { and sending them on to Grand Falls - there is no } \\
\text { contingency plan in the case of her absence. }\end{array}$ \\
\hline Medium & $\begin{array}{l}\text { Cost of implementing the system } \\
\text { is much higher than anticipated }\end{array}$ & $\begin{array}{l}\text { The ACE-1 and TimberSmart components of the system } \\
\text { will be costly but necessary. The proposed Grand Falls' } \\
\text { upgrade is unpredictable because of its scale but has been } \\
\text { quoted as high risk - in costs and complexity. }\end{array}$ \\
\hline \multirow[t]{3}{*}{ Low } & $\begin{array}{l}\text { Orders are lost between Mayhills } \\
\text { and Juke Timbers }\end{array}$ & $\begin{array}{l}\text { A notification of receipt should occur at all stages of the } \\
\text { system where one entity sends data to another. }\end{array}$ \\
\hline & $\begin{array}{l}\text { Jessica Webber does not cope } \\
\text { with the volume of orders. }\end{array}$ & $\begin{array}{l}\text { Jessica is the only person indicated as receiving orders via } \\
\text { TimberSmart. It must be ensured that the volume of orders } \\
\text { to be processed does not exceed Jessica or TimberSmart's } \\
\text { capabilities, or more staff will be required. }\end{array}$ \\
\hline & Stability of the ACE-1 system & $\begin{array}{l}\text { The projected flow of information needs to be measured in } \\
\text { order to stress test the network. }\end{array}$ \\
\hline \multicolumn{3}{|c|}{ Probability of Occurrence - Opportunities } \\
\hline Estimation & Description & Indicators \\
\hline High & $\begin{array}{l}\text { Huge boost in sales for Juke } \\
\text { Timbers }\end{array}$ & $\begin{array}{l}\text { Mayhill's will be Juke Timbers' largest client if the } \\
\text { process is managed correctly. }\end{array}$ \\
\hline High & $\begin{array}{l}\text { Huge boost to reputation and } \\
\text { credibility }\end{array}$ & The possibility of developing other large-volume clients \\
\hline
\end{tabular}


Figure 1: Electronic Links Required by ACE Technologies Ltd

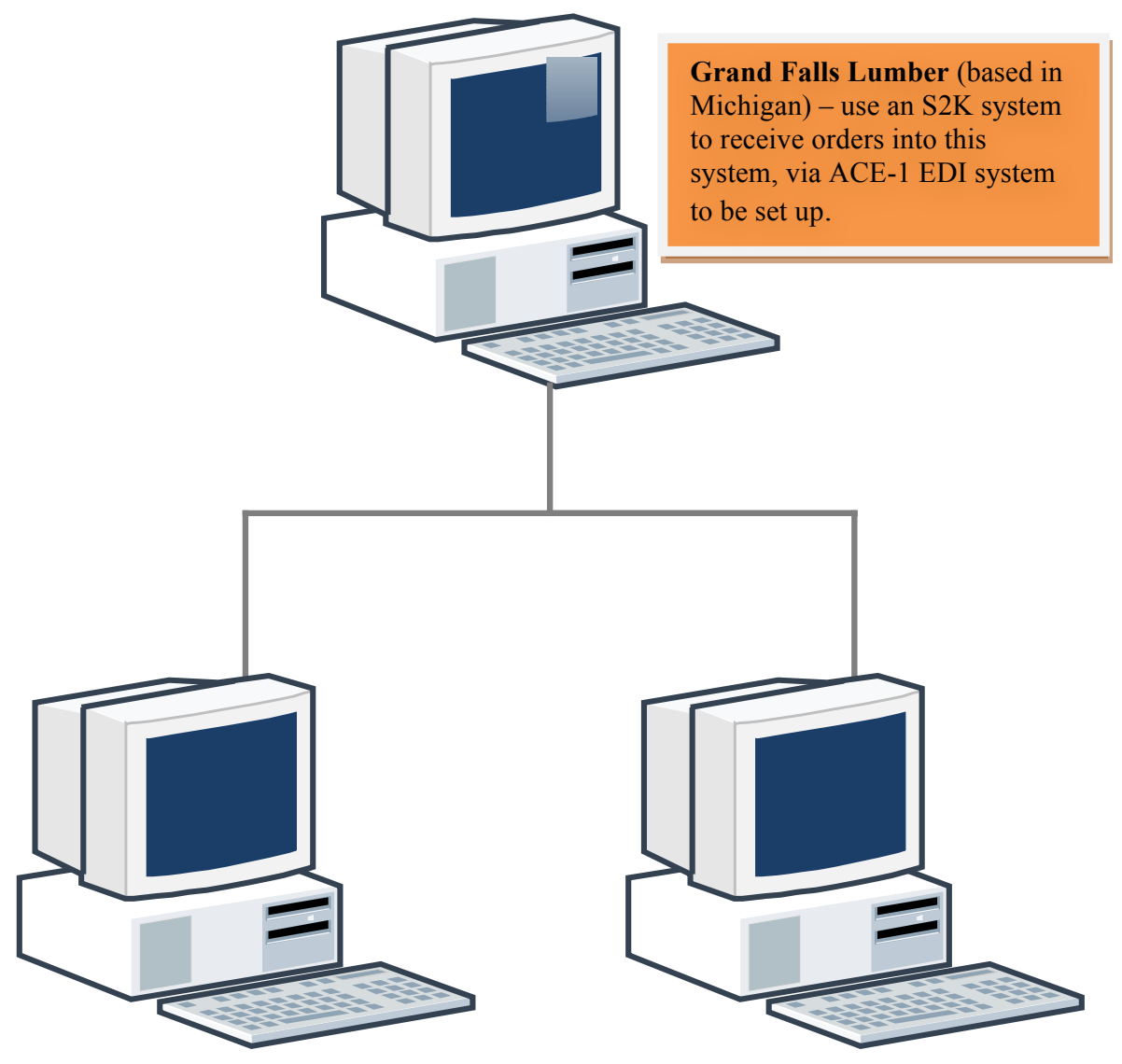

Mayhill's (.U.S hardware

retailer) - Operates an EDI AS2

system to send purchase orders

to Juke Timbers Ltd via Grand

Falls

Juke Timbers. (In New Zealand and Jessica their US-based

account manager) - use a

TimberSmart system to receive orders via ACE-1, electronic data interchange 